\title{
Insulin impairs the maturation of chondrocytes in vitro
}

E.S. Torres ${ }^{1}$, C.V. Andrade ${ }^{1}$, E.C. Fonseca ${ }^{1}$, M.A. Mello ${ }^{1}$ and M.E.L. Duarte ${ }^{2,3}$

\author{
'Departamento de Patologia, Universidade Federal Fluminense, \\ Niterói, RJ, Brasil \\ ${ }^{2}$ Programa Avançado de Biologia Celular Aplicada à Medicina, \\ Hospital Universitário Clementino Fraga Filho, and \\ ${ }^{3}$ Departamento de Histologia e Embriologia, \\ Universidade Federal do Rio de Janeiro, Rio de Janeiro, RJ, Brasil
}

\section{Correspondence \\ M.E.L. Duarte \\ PABCAM, UFRJ \\ Hospital Universitário, 4 o andar \\ Av. Brigadeiro Trompowsky, s/n \\ Ilha do Fundão \\ 21941-970 Rio de Janeiro, RJ \\ Brasil \\ Fax: +55-21-2610-4593 \\ E-mail: eugenia@urbi.com.br \\ Research supported in part by \\ CAPES, CNPq and FINEP.}

Received September 4, 2002

Accepted April 24, 2003

\begin{abstract}
The precise nature of hormones and growth factors directly responsible for cartilage maturation is still largely unclear. Since longitudinal bone growth occurs through endochondral bone formation, excess or deficiency of most hormones and growth factors strongly influences final adult height. The structure and composition of the cartilaginous extracellular matrix have a critical role in regulating the behavior of growth plate chondrocytes. Therefore, the maintenance of the threedimensional cell-matrix interaction is necessary to study the influence of individual signaling molecules on chondrogenesis, cartilage maturation and calcification. To investigate the effects of insulin on both proliferation and induction of hypertrophy in chondrocytes in vitro we used high-density micromass cultures of chick embryonic limb mesenchymal cells. Culture medium was supplemented with $1 \% \mathrm{FCS}+60$ $\mathrm{ng} / \mathrm{ml}(0.01 \mu \mathrm{M})$ insulin and cultures were harvested at regular time points for later analysis. Proliferating cell nuclear antigen immunoreactivity was widely detected in insulin-treated cultures and persisted until day 21 and $\left[{ }^{3} \mathrm{H}\right]$-thymidine uptake was highest on day 14 . While apoptosis increased in control cultures as a function of culture time, terminal deoxynucleotidyl transferase-mediated dUTP nick end labeling (TUNEL)-labeled cells were markedly reduced in the presence of insulin. Type II collagen production, alkaline phosphatase activity and cell size were also lower in insulin-treated cultures. Our results indicate that under the influence of $60 \mathrm{ng} / \mathrm{ml}$ insulin, chick chondrocytes maintain their proliferative potential but do not become hypertrophic, suggesting that insulin can affect the regulation of chondrocyte maturation and hypertrophy, possibly through an antiapoptotic effect.
\end{abstract}

\section{Introduction}

A large number of growth factors, cytokines and hormones are implicated in the regulation of endochondral ossification (1). In this highly regulated process, mesenchy-
Key words

- Chondrocytes

- Insulin

- Micromass cultures

- Apoptosis mal cells differentiate into chondrocytes that proliferate, mature, become hypertrophic and deposit large amounts of extracellular matrix (ECM) which is finally calcified, and replaced by bone (2).

Several in vitro systems have been used 
to reproduce the events that occur during endochondral ossification (3-6). Nevertheless, the maintenance of the three-dimensional cell-matrix interaction is needed for chondrogenesis, cartilage maturation and calcification. Chondrocytes kept in monolayer cultures gradually lose the cartilage phenotype and begin to dedifferentiate, resembling mesenchymal cells (7) and producing molecules not characteristic of cartilage (8).

Ahrens et al. (9) developed an in vitro system of high-density micromass cultures of chick embryonic limb mesenchyme. This system has been widely used to study chondrogenesis $(10,11)$ and more recently $(12,13)$ was used to study the process of cartilage maturation since it permits the observation of the continuous process of differentiation, maturation and calcification.

The identification of insulin and insulin receptors in the chick embryo within $48 \mathrm{~h}$ after fertilization demonstrates that, at physiological concentrations, insulin may act as a mitogen for some fetal cell types $(14,15)$. At low concentrations, insulin increases parameters of growth, metabolism and muscle differentiation in 4-day-old chick embryos (16). Insulin has been shown to have an in vitro stimulatory effect on chondrocyte proliferation and activity and an in vivo effect on growth plate width (17). Also, situations of hypoinsulinemia (insulin-dependent diabetes mellitus) and hyperinsulinemia with or without non-insulin-dependent diabetes considerably alter normal bone physiology (18).

In the present study we have investigated the in vitro effects of insulin on chondrocyte proliferation, maturation, hypertrophy and apoptosis in the established system of highdensity micromass cultures of chicken limb bud mesenchymal cells.

\section{Material and Methods}

\section{Micromass culture}

Limb buds were removed from Ham-
burger-Hamilton stage 23-24 chicken embryos (19) and the starting cell population consisting of mesenchymal cells was placed in calcium-magnesium-free saline glucose (CMFSG) solution. The buds were dissociated enzymatically in $0.1 \%(\mathrm{w} / \mathrm{v})$ collagenase (Sigma, St. Louis, MO, USA) and 0.1\% (w/v) trypsin (Sigma) in CMFSG. The cell suspension was filtered through a $20-\mu \mathrm{m}$ nitex filter and centrifuged for $10 \mathrm{~min}$ at $600 \mathrm{~g}$. The pellets were resuspended in CMFSG with $10 \%$ FCS and cell density was adjusted to $25-30 \times 10^{6}$ cells $/ \mathrm{ml}$. The cells were plated as a micromass ( $10 \mu \mathrm{l}$ of the cell suspension) onto 24-well plates and allowed to attach for $1-2 \mathrm{~h}$ at $37^{\circ} \mathrm{C}$ in a $5 \% \mathrm{CO}_{2}$ atmosphere. After incubation the cells were fed with DMEM/ F-12 medium (Sigma) containing $100 \mathrm{U} / \mathrm{ml}$ penicillin, $100 \mu \mathrm{g} / \mathrm{ml}$ streptomycin and $10 \%$ FCS. From day 2 on, the medium was supplemented with $2.5 \mathrm{mM}$ ß-glycerophosphate and $25 \mu \mathrm{g} / \mathrm{ml}(0.15 \mathrm{mM})$ ascorbate (Sigma). To support chondrogenesis, before starting the treatment with insulin, all cultures were fed until day 3 with medium containing $10 \%$ FCS. From day 4 on the cultures were treated with $1 \% \mathrm{FCS}$ and $1 \% \mathrm{FCS}+60 \mathrm{ng} / \mathrm{ml}(0.01 \mu \mathrm{M})$ insulin, respectively. Cultures were maintained for up to 21 days and were harvested at regular time points (days 7, 14 and 21) for analysis of growth and maturation status.

\section{Fixation and embedding}

The micromass cultures were rinsed three times in PBS and fixed in 4\% (v/v) paraformaldehyde for $1 \mathrm{~h}$. Subsequently they were released gently from the well with a cell scraper, dehydrated in graded series of ethanol, cleared in xylene and embedded in paraffin. Specimens were cut into $4-\mu \mathrm{m}$ sections for all histological procedures.

\section{Phenotypic characterization of the cells in} culture

Cell morphology. Histological sections 
were stained with hematoxylin-eosin to analyze cell morphology and with Alcian blue, pH 1.0 (20), to detect sulfated glycosaminoglycans in the cartilage matrix.

Type II collagen expression. Collagen type II deposition was detected by immunohistochemistry with a polyclonal rabbit antibovine type II collagen antibody (Chemicon, Temecula, CA, USA) at 1:150 dilution for $30 \mathrm{~min}$ at $37^{\circ} \mathrm{C}$. The primary antibody was detected with biotinylated secondary rabbit anti-mouse IgG, 1:200 (Dako, Carpinteria, CA, USA), whereas negative control sections were stained using PBS containing 1\% BSA instead of the primary antibody. Normal hyaline cartilage slides were used as positive control.

\section{Cell proliferation}

$\left[{ }^{3} \mathrm{H}\right]$-thymidine uptake. Cultures were incubated for $24 \mathrm{~h}$ with medium containing $0.25 \mu \mathrm{Ci} / \mathrm{ml}\left[{ }^{3} \mathrm{H}\right]$-thymidine (TRK 418 Amersham Pharmacia, Arlington Heights, IL, USA). The radioactivity incorporated was measured by liquid scintillation counting using a Tri-Carb 2100 TR liquid scintillation analyzer (Perkin Elmer, Boston, MA, USA) for $2 \mathrm{~min}$.

Proliferating cell nuclear antigen (PCNA) expression. Sections were incubated overnight with anti-mouse PCNA (Dako) as the primary antibody at 1:3000 dilution in PBSBSA at $4^{\circ} \mathrm{C}$. Negative control sections were stained using PBS containing 1\% BSA instead of the primary antibody. Slides from a human glioblastoma were used as positive control.

\section{Cell hypertrophy}

Alkaline phosphatase activity. At $4^{\circ} \mathrm{C}$, cells were rinsed in PBS, extracted with $0.5 \%$ Triton X-100 (Sigma) in 0.5 M Tris$\mathrm{HCl}, \mathrm{pH}$ 8.0, mechanically homogenized, sonicated for $30 \mathrm{~s}$, and centrifuged for $5 \mathrm{~min}$ at $4^{\circ} \mathrm{C}$ at $13,000 \mathrm{~g}$, and 5-, 10- and $15-\mu \mathrm{l}$ aliquots of the supernatant were used for spectrophotometric enzyme assay (Biobrás, São Paulo, SP, Brazil). The alkaline phosphatase activity was determined as the amount of p-nitrophenol released from the substrate p-nitrophenyl phosphate on the basis of absorbance at $405 \mathrm{~nm}$ in a microplate reader (Model 450, BioRad, Hercules, CA, USA) and activity is reported per minute per $\mathrm{mg}$ protein. Protein was determined by the micro-BCA assay (Pierce Chemical, Rockford, IL, USA) in the working range 25$2000 \mu \mathrm{g} / \mathrm{ml}$ of BSA at $560 \mathrm{~nm}$.

\footnotetext{
Table 1. Semiquantitative analysis of selected histological indexes demonstrating the deposition of extracellular matrix, expression of type II collagen, cell proliferation and apoptosis with time in culture.

\begin{tabular}{|c|c|c|c|c|c|c|}
\hline & \multicolumn{2}{|c|}{ Day 7} & \multicolumn{2}{|c|}{ Day 14} & \multicolumn{2}{|c|}{ Day 21} \\
\hline & Control & Insulin & Control & Insulin & Control & Insulin \\
\hline Extracellular matrix ${ }^{1}$ & - & - & ++ & + & ++ & + \\
\hline Type II collagen ${ }^{2}$ & - & - & ++ & - & ++ & + \\
\hline PCNA & ++ & ++ & + & ++ & + & ++ \\
\hline Apoptosis ${ }^{3}$ & + & + & ++ & + & ++ & - \\
\hline
\end{tabular}

PCNA, proliferating cell nuclear antigen. Semiquantitative parameters: $(-)$ absent or weak, $(+)$ moderate, $(++)$ intense.

Control: $1 \%$ FCS treated cultures.

Insulin: $1 \%$ FCS $+60 \mathrm{ng} / \mathrm{ml}(0.01 \mu \mathrm{M})$ insulin.

${ }^{1}$ Amount of extracellular matrix positively stained by Alcian blue at $\mathrm{pH} 1.0$.

${ }^{2}$ Type II collagen expression detected by immunohistochemistry.

${ }^{3}$ Cells positively labeled by the TUNEL procedure.
} 
Cell size. Mean cell size $( \pm \mathrm{SD})$ was determined by measuring cell diameter microscopically (magnification 40X) at each culture time point $(\mathrm{N} \geq 100$ cells/culture).

\section{Apoptosis}

Internucleosomal DNA degradation was assessed by terminal deoxynucleotidyl transferase-mediated dUTP nick end labeling (TUNEL) (21). Histological sections (4 $\mu \mathrm{m})$ were incubated with terminal transferase to

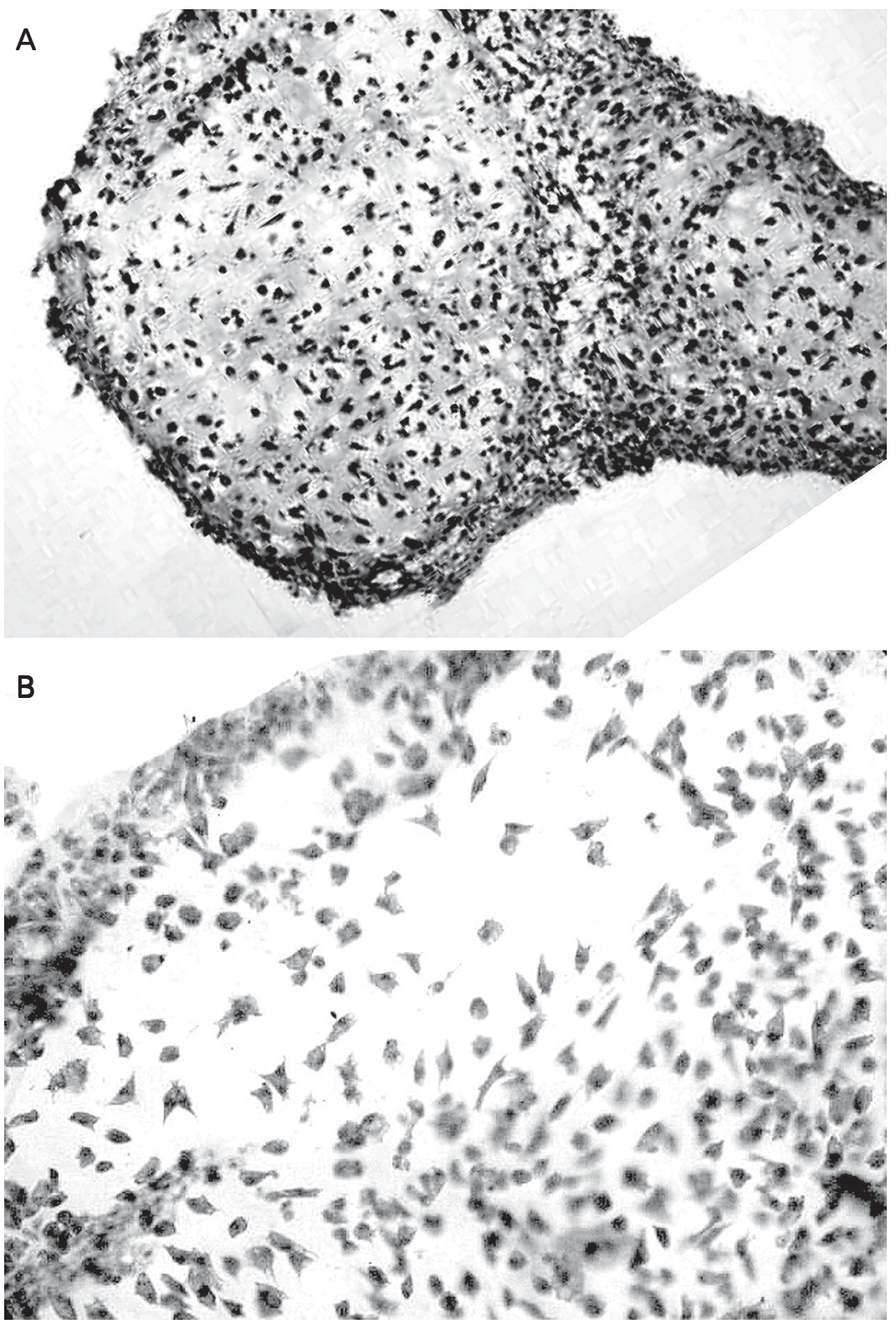

label the 3'-end of fragmented nuclear DNA with the ApopTag plus peroxidase in situ apoptosis detection kit (Intergen, Purchase, NY, USA) following the manufacturer's recommendations, including the proteinase $\mathrm{K}$ step for 4 min. Rodent mammary gland slides were used as a positive control.

\section{Statistical analysis}

All values were analyzed by the paired Student $t$-test, with the level of significance set at $\mathrm{P}<0.05$.

\section{Results}

\section{Micromass culture morphology and extracellular matrix deposition}

At day 2, phase contrast microscopy revealed distinct cartilaginous aggregates of whole mount cultures. On day 14 , cartilage nodules stained positively for Alcian blue, demonstrating the presence of sulfated proteoglycans and thus confirming the cartilaginous origin or the matrix.

At day 21, light microscopy revealed the presence of round-shaped cells surrounded by ECM, resembling cartilage in vivo (Figure 1A). The amount of ECM increased as a function of time in all cultures, though less conspicuously in insulin-treated cultures (Figure $1 \mathrm{~B}$ and Table 1).

Type II collagen was expressed in control cultures by day 14 and persisted up to day 21. Under the influence of insulin, type II collagen was labeled with the polyclonal antibody only on day 21 (Table 1).

Figure 1. Micromass culture morphology and extracellular matrix deposition at day 21. A, Well-organized cartilage nodules resembling cartilage in vivo were formed in $1 \%$ FCS control cultures. $B$, In contrast, in insulin-treated cultures hypertrophic cells are scarce and the nodular organization is lacking, suggesting impaired cell maturation. Hematoxylin-eosin. Final magnification: 10X (A) and 40X (B). 


\section{Cell proliferation}

The results for PCNA immunostaining in all cultures and at different time points are presented in Table 1. At day 7 all cultures had a similar appearance with numerous cells positively stained for PCNA. Whereas the number of proliferating cells positively stained for PCNA gradually diminished in $1 \%$ FCS control cultures (Figure 2A), in insulin-treated cultures a high number of proliferating cells persisted up to day 21 (Figure 2B).

The rate of DNA synthesis, assessed by $\left[{ }^{3} \mathrm{H}\right]$-thymidine uptake by the cultures, is shown in Figure 3. Under the influence of insulin, a statistically significant increase in DNA synthesis $(\mathrm{P}<0.05)$ was observed at day 14.

\section{Hypertrophy}

At day 14, alkaline phosphatase activity was significantly lower $(\mathrm{P}<0.05)$ (Figure 4) in insulin-treated cultures. Cell diameter was significantly smaller $(\mathrm{P}<0.001$ and $\mathrm{P}<0.05$ at days 14 and 21, respectively) (Figure 5) in insulin-treated cultures compared to $1 \%$ FCS control cultures.

\section{Apoptosis}

Internucleosomal fragmented DNA was detected by TUNEL after day 7 in all cultures. With time, apoptotic cells increased in $1 \%$ FCS control cultures (Table 1) and corresponded to apoptosis identified by nuclear

Figure 2. Analysis of cell proliferation of chick limb mesenchyme. In later stages (day 21), when cell maturation prevails over cell proliferation, the number of proliferating cells positively stained for proliferating cell nuclear antigen (PCNA) gradually diminished in 1\% FCS control cultures (A). In insulin-treated cultures a high number of proliferating cells (dark cells) persisted up to day 21 (B). PCNA immunohistochemistry counterstained with Mayer's hematoxylin. Final magnification: 10X ( $\mathrm{A}$ and $\mathrm{B}$ ). morphology in hematoxylin/eosin-stained sections. At day 21, the amount of apoptotic cells was distinctly smaller in insulin-treated cultures than in control cultures (Table 1).

\section{Discussion}

The present results demonstrate that insulin at the concentration of $60 \mathrm{ng} / \mathrm{ml}(0.01$ $\mu \mathrm{M})$ is mitogenic to chondrocytes and downregulates chondrocyte maturation possibly through an antiapoptotic effect.
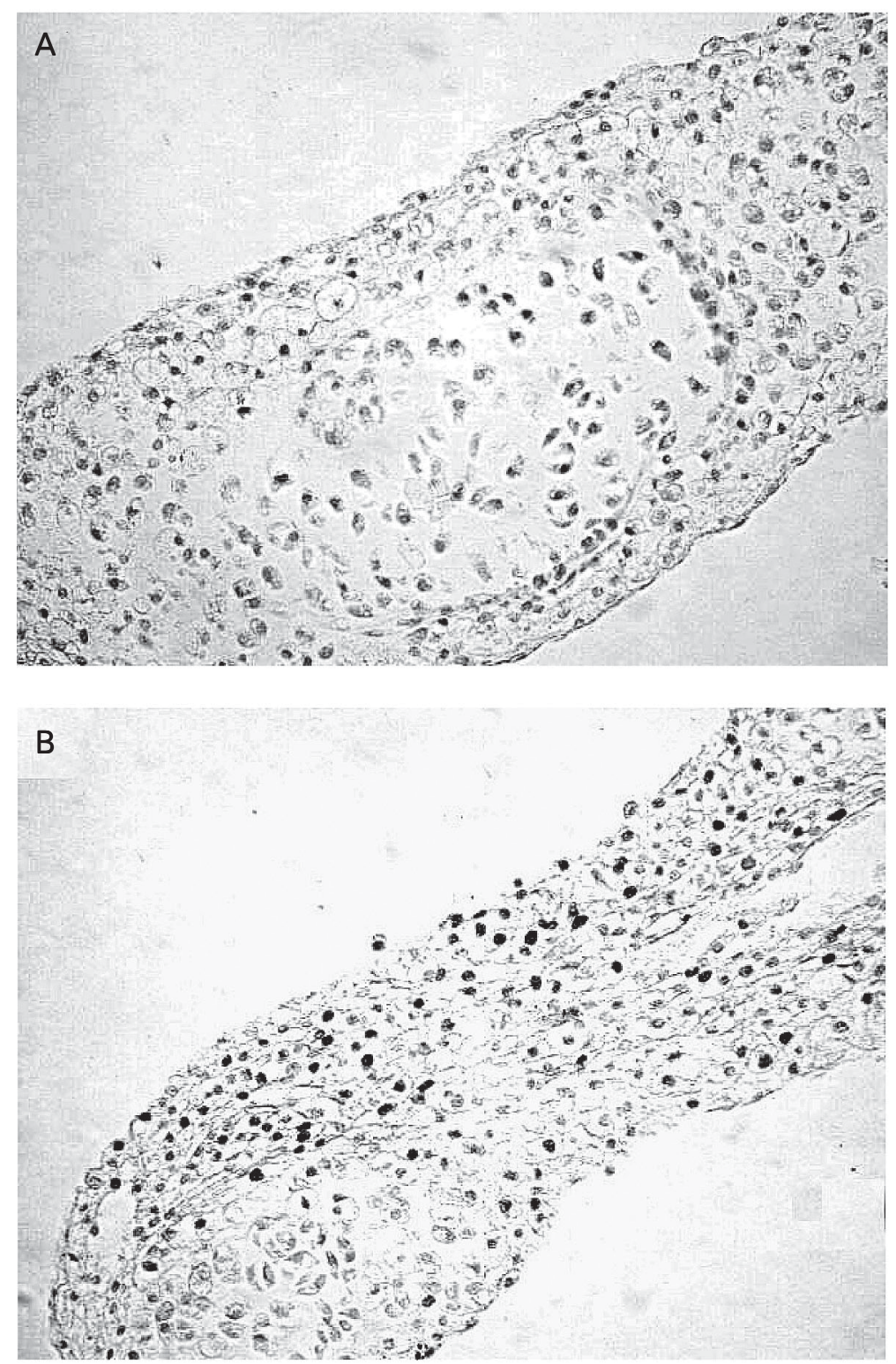
Figure 3. Effect of insulin and $1 \%$ FCS on DNA synthesis in chondrocyte micromass cultures. Data are reported as means $\pm \mathrm{SD}$ for $\mathrm{N}=6$. Chondrocytes responded to insulin by increasing DNA synthesis at day $14(P<0.05)$
In the model utilized in this study (12), the cells derived from mesenchymal embryonic chick limb buds were prepared in micromass cultures. During the first 2 days of culture, aggregates were formed that ultimately differentiated into cartilage nodules consisting of round-shaped cells surrounded by ECM and resembling cartilage in vivo. In these high-density cultures, cell contact and the secretion of macromolecules into the microenvironment control cell growth and differentiation. Mesenchymal cells obtained from limb buds at stage 24 are phenotypically committed to turning into cartilage and, indeed, in culture systems cartilage develops as the major phenotype. On the other hand,

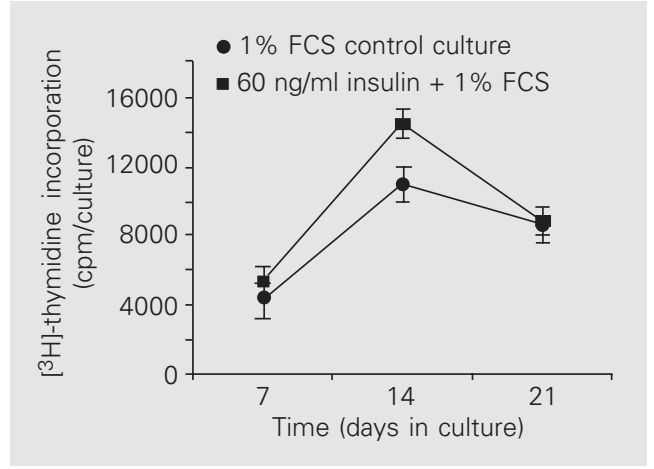

Figure 4. Effect of insulin and 1\% FCS on alkaline phosphatase (AP) specific activity in micromass cultures of chick embryonic limb mesenchyme. Data are reported as means $\pm S D$ for $N=6$. On day 14 the increase in AP specific activity was significantly greater $(P<0.05)$ in control cultures.

Figure 5. Effect of insulin and culture time on cell size. The cells treated with insulin were significantly smaller on days 14 $(P<0.001)$ and $21(P<0.05)$, respectively, compared to control. Cell sizes were calculated based on the assumption that chondrocytes were spherical in shape. One hundred cells were measured at each time point in each culture. Data are reported as mean \pm SD for 10 independent experiments. Open columns, $1 \%$ FCS; closed columns, $60 \mathrm{ng} / \mathrm{ml}$ insulin. the cells not committed to the chondrogenic lineage and present in the original heterogeneous population were possibly prevented from proceeding through the maturation process either because of their peripheral position in the aggregates or by a sorting out mechanism (22). An additional convenience of this culture system is to repeatedly follow an expected pattern of growth and differentiation and to achieve cartilage formation as a uniform three-dimensional tissue. In this micromass system, mesenchymal cells chondrified, matured, and sustained hypertrophy as single cartilage nodules distributed randomly within the culture (12). Since this system closely reproduces the entire history of the chondrocyte, including cell morphology, matrix deposition and programmed cell death, it becomes a highly suitable model for the study of chondrocyte maturation under the influence of insulin.

The role of insulin as a growth-regulating hormone has been well established. Quarto et al. (23) demonstrated that insulin is a primary factor involved in the onset and progression of chondrogenesis. They also postulated that insulin acts directly on chondrocyte maturation without utilizing the secondary pathway of binding to IGF-I receptors. Indeed, in vivo (17) but not in vitro (24), the local production of IGF-I is apparently necessary for the growth-promoting role of insulin. Quarto et al. (25) also showed that FGF-2 induces chondrocyte proliferation if associated with insulin. Their findings demonstrated that FGF-2 does not induce cell proliferation by itself but must be associated with insulin, thus demonstrating a synergistic effect of the two factors. Insulin availability is also intimately linked to the progression of normal and aberrant fetal growth. Hill and De Sousa (26) suggested that physiological concentrations of insulin might exert direct growth-promoting actions on the epiphyseal growth plates of the fetal lamb.

The experiments reported here show that, under the influence of low concentration of 
insulin $(60 \mathrm{ng} / \mathrm{ml})$, chondrocytes proliferate but exhibit a significant impairment of maturation. This view is supported by the findings of lower alkaline phosphatase activity, lower mean cell diameter and reduced synthesis of type II collagen. Whereas in $1 \%$ FCS cultures the number of proliferating cells positively stained for PCNA was reduced over time, in insulin-treated cultures the level of cell proliferation was sustained throughout the period of observation.

The rate of DNA synthesis, assessed by $\left[{ }^{3} \mathrm{H}\right]$-thymidine uptake, was also significantly higher under the influence of insulin. Hill and De Sousa (26) showed that fetal tissues are more sensitive to the trophic effects of insulin and that, at physiological concentrations, insulin has a mitogenic action on isolated fetal lamb epiphyseal chondrocytes. Ballock and Reddi (3) also observed that insulin maintained chondrocyte viability in the absence of cell hypertrophy.

In vivo and in vitro studies have demonstrated that terminally differentiated chondrocytes undergo programmed cell death $(12,27)$. In vivo studies have shown that in the proximal tibial growth plate of young chicks, terminally differentiated chondrocytes undergo programmed cell death $(28,29)$. This process possibly provides a physiological mechanism for the rapid and controlled removal of terminally differentiated cells.

In the present study cell apoptosis was detected by the ApopTag Plus method which is based on the specific staining of frag- mented DNA. The ability to observe the chondrocytes as a uniform three-dimensional tissue enabled us to visualize apoptosis at the single cell level. Also, we were able to rule out the possibility of DNA damage caused by artifacts generated by tissue digestion, cell isolation procedures, and activation of endogenous nuclease activity. The treatment with insulin was associated with an increased number of proliferating chondrocytes and a relatively low level of apoptosis.

Taken together, the data presented here suggest that insulin regulates chondrocyte maturation and hypertrophy through a possible antiapoptotic effect. Bertrand et al. $(30,31)$ provided the first evidence of the antiapoptotic function of insulin. These investigators postulate that this antiapoptotic action involves the activation by insulin of nuclear factor $\mathrm{\kappa B}$, a transcription factor playing a critical role in apoptosis inhibition. Yenush et al. (32) also raised the possibility that a phosphotyrosine-independent mechanism promotes the antiapoptotic and growth actions of insulin. Additional studies will be necessary to further elucidate the precise role of insulin in the control of chondrocyte maturation for the induction of growth-promoting effects on the epiphyseal growth plate.

\section{Acknowledgments}

The authors thank A. Cohen and A. Balduíno for a critical reading of the manuscript.

\section{References}

1. Trippel SB, Wroblewski J, Makower A, Whelan MC, Schoenfeld D \& Doctrow SR (1993). Regulation of growth-plate chondrocytes by insulin-like growth factor I and basic fibroblast growth factor. Journal of Bone and Joint Surgery, 2: 177-189.

2. Schmid TM \& Linsenmayer TF (1985). Immunohistochemical localization of short-chain collagen (type $X$ ) in avian skeletal tissue. Journal of Cell Biology, 100: 598-605.

3. Ballock RT \& Reddi AH (1994). Thyroxine is the serum factor that regulates morphogenesis of columnar cartilage from isolated chondrocytes in chemically defined medium. Journal of Cell Biology, 126: $1311-1318$
4. Kato $Y$, Iwamoto $M$ \& Koike $T$ (1998). Terminal differentiation and calcification in rabbit chondrocyte cultures grown in centrifuge tubes: regulation by transforming growth factor $B$ and serum factors. Proceedings of the National Academy of Sciences, USA, 85: 9552-9556.

5. Alini M, Carey D, Hirata S, Grympas MD, Pidoux I \& Poole AR (1994). Cellular and matrix changes before and at the time of calcification in the growth plate studied in vitro: arrest of type $X$ collagen synthesis and net loss of collagen when calcification is initiated. Journal of Bone and Mineral Research, 9: 1077-1087.

6. Roark EF \& Greer K (1994). Transforming growth factor $\beta$ and bone 
morphogenetic protein-2 act by distinct mechanisms to promote chick limb cartilage differentiation in vitro. Developmental Dynamics, 200: 103-116.

7. Holtzer H, Abbott J, Lash J \& Holtzer S (1960). The loss of phenotypic traits by differentiated cells in vitro. I. Differentiation of cartilage cells. Proceedings of the National Academy of Sciences, USA, 46: 1533-1542.

8. Mayne R, Vail MS, Mayne P \& Miller EJ (1976). Changes in the type of collagen synthesized as clones of chick chondrocytes grow and eventually lose division capacity. Proceedings of the National Academy of Sciences, USA, 73: 1674-1678.

9. Ahrens PB, Solursh M \& Reiters R (1977). Stage-related capacity for limb chondrogenesis in cell culture. Developmental Biology, 60: 6982.

10. San Antonio JD \& Tuan RS (1986). Chondrogenesis of limb mesenchyme in vitro: stimulation by cations. Developmental Biology, 115: 313-324.

11. Wong M \& Tuan RS (1993). Nuserum, a synthetic serum replacement, supports chondrogenesis of embryonic chick limb bud mesenchymal cells in micromass cultures. In Vitro Cellular and Developmental Biology. Animal, 29: 917-922.

12. Mello MA \& Tuan RS (1999). High-density micromass cultures of embryonic limb bud mesenchymal cells: an in vitro model of endochondral skeletal development. In Vitro Cellular and Developmental Biology. Animal, 35: 262-269.

13. Boskey AL, Stiner D, Doty SB, Binderman I \& Leboy P (1992). Studies of mineralization in tissue culture: optimal conditions for cartilage calcification. Bone and Mineral, 16: 11-36.

14. De Pablo F, Roth J, Hernandez E \& Pruss RM (1982). Insulin is present in chick eggs and early chick embryos. Endocrinology, 111: 1909-1911.

15. Bassas L, De Pablo F, Lesniak MA \& Roth J (1985). Ontogeny of receptors for insulin-like growth factor over insulin receptors in brain. Endocrinology, 117: 2321-2329.

16. Girbau M, Gomez JA, Lesniak MA \& De Pablo F (1987). Insulin and insulin-like growth factor I both stimulate metabolism, growth and differentiation in the post neurula chick embryo. Endocrinology, 121: 1477-1483.

17. Alarid ET, Schlechter NL, Russell SM \& Nicoll CS (1992). Evidence suggesting that insulin-like growth factor-I is necessary for the trophic effects of insulin on cartilage growth in vivo. Endocrinology, 130: 2305-2309.

18. Verhaeghe $J$ \& Bouillon R (1996). Principles of bone biology. In: Bilezikian JP, Raisz LG \& Rodan GA (Editors), Effects of Diabetes and Insulin on Bone Metabolism. Academic Press, San Diego, CA, USA.

19. Hamburger $V$ \& Hamilton $H L$ (1951). A series of normal stages in the development of the chick embryo. Journal of Morphology, 88: 49-92.
20. Cook HC (1996). Carbohydrates. In: Bancroft JD \& Stevens A (Editors), Theory and Practice of Histological Techniques. Churchill Livingstone, New York.

21. Gavrieli $Y$, Sherman $Y$ \& Ben-Sasson SA (1992). Identification of programmed cell death in situ via specific labeling of nuclear DNA fragmentation. Journal of Cell Biology, 119: 493-501.

22. Tacchetti C, Quarto R, Nitsch L, Hartmann DJ \& Cancedda R (1987). In vitro morphogenesis of chick embryo hypertrophic chondrocytes. Journal of Cell Biology, 105: 999-1006.

23. Quarto R, Campanile G, Cancedda R \& Dozin B (1992). Thyroid hormone, insulin and glucocorticoids are sufficient to support chondrocyte differentiation to hypertrophy: a serum-free analysis. Journal of Cell Biology, 119: 989-995.

24. Böhme K, Conscience-Egli M, Tshan T, Winterhalter KH \& Bruckner $P$ (1992). Induction of proliferation or hypertrophy of chondrocytes in serum-free culture: the role of insulin-like growth factor-l, insulin, or thyroxine. Journal of Cell Biology, 116: 1035-1042.

25. Quarto R, Campanile G, Cancedda R \& Dozin B (1997). Modulation of commitment, proliferation, and differentiation of chondrogenic cells in defined culture medium. Endocrinology, 138: 4966-4976.

26. Hill DJ \& De Sousa D (1990). Insulin is a mitogen for isolated epiphyseal growth plate chondrocytes from the fetal lamb. Endocrinology, 126: 2661-2670.

27. Lewinson D \& Silbermann M (1992). Chondroclasts and endothelial cells collaborate in the process of cartilage resorption. Anatomical Record, 233: 504-514

28. Hatori M, Klatte KJ, Teixeira CC \& Shapiro IM (1995). End labeling studies of fragmented DNA in the avian growth plate: evidence of apoptosis in terminally differentiated chondrocytes. Journal of Bone and Mineral Research, 10: 1960-1968.

29. Roach $H$ (1997). New aspects of endochondral ossification in the chick: chondrocyte apoptosis, bone formation by former chondrocytes, and acid phosphatase activity in the endochondral bone matrix. Journal of Bone and Mineral Research, 12: 795-805.

30. Bertrand F, Atfi A, Cadoret A, L'Allemain G, Robin H, Lascols O, Capeau J \& Cherqui G (1998). A role for nuclear factor $\kappa B$ in the antiapoptotic function of insulin. Journal of Biological Chemistry, 273: 2931-2938.

31. Bertrand F, Desbois-Mouthon C, Cadoret A, Prunier C, Robin H, Capeau J, Atfi A \& Cherqui G (1999). Insulin antiapoptotic signaling involves insulin activation of the nuclear factor $\kappa B$-dependent survival genes encoding tumor necrosis factor receptor-associated factor 2 and manganese-superoxide dismutase. Journal of Biological Chemistry, 274: 30596-30602.

32. Yenush L, Zanella G, Uchida T, Bernal D \& White MF (1998). The pleckstrin homology and phosphotyrosine binding domains of insulin receptor substrate 1 mediate inhibition of apoptosis by insulin. Molecular and Cellular Biology, 18: 6784-6794. 